\title{
Perception of Universitas Padjadjaran Students towards Psychotic Disorders
}

\author{
Renzavaldy Rusly, ${ }^{1}$ Veranita Pandia, ${ }^{2}$ Deni Kurniadi Sunjaya ${ }^{3}$ \\ ${ }^{1}$ Leuwiliang District Hospital, West Bogor, ${ }^{2}$ Departement of Psychiatry Faculty of Medicine \\ Universitas Padjadjaran/Dr.Hasan Sadikin General Hospital, Bandung ${ }^{3}$ Department of Public \\ Health Faculty of Medicine Universitas Padjadjaran Bandung, Indonesia
}

\begin{abstract}
Background: Psychotic disorders have a very high incidence in Indonesia and arethe first rank in terms of the global burden of disability. Students are the frontline in the face of society. The formation of stigma and discrimination is rooted from bad perceptions. The aim of this study was to determine and measure Universitas Padjadjaran students' perceptions towards psychotic disorders and find out why these perceptions can be shaped.

Methods: The design of study was a sequential explanatory mixed method research. The population of this study is glittering Universitas Padjadjaran students who were in Jatinangor between batches 2011 to 2013. Samples were taken using cluster and stratified random sampling. Quantitative data retrieval was collected by using a self-administered questionnaire. Next, there would be focused group discussions and in-depth interviews which discussed the results of the quantitative data collection then interpreted them qualitatively.

Result: The percentage of students at Universitas Padjadjaran with perception of psychotic disorders in good category was $19.04 \%, 80.96 \%$ unfavorable category, and bad $0 \%(n=126)$. Besides various relevant opinion found why these perceptions were formed, such as a lack of education on students towards psychotic disorders, the existence of stigma based on life experience of psychotic patients, the lack of social media and physical campaign towards the psychotic disorders.

Conclusions: The perception of Universitas Padjadjaran students towards psychotic disorders is still relatively unfavorable, therefore literation towards psychotic disorders should be provided through education, campaigns, social media utilization by psychiatrists and the government.
\end{abstract}

Keywords: Perception, psychotic disorders, university students

\section{Introduction}

The World Health Organization ${ }^{1}$ (WHO) stated that the number of people with psychotic disorders around the world is 24 million people, and this number is projected to increase rapidly. The psychotic disorder was ranked first in the world burden in terms of disability by $13 \%$ of the population. A psychotic disorder was mostly experienced at the age of childbearing. In male it started at the average age of 25.4 years and in female at 27.5 years. According to Riset Kesehatan Dasar $^{2}$ (RKD)2013, the prevalence of psychotic disorders in Indonesia was 1.7 per mile area. West Java ranked high among all the provinces in Indonesia which is 1.6 per mile area. In
Sumedang ${ }^{2}$, the number of psychotic disorders was $0.8 \%$ of the entire population.

Many recurrences of psychotic disorder were caused by the behavior of the community in the form of stigma and discrimination. It was likely preceded by an initial negative perception towards people with psychotic disorders. The prevalence of psychotic disorder at the high productive age, and the many factors that could lead to the perception of the problem were the main reasons for conducting a study to determine the perception of students at Universitas Padjadjaran toward psychotic disorder as the agent of change, the guardian of values, and iron stock for this nation so that the problem could be overcame well. ${ }^{3}$ 


\section{Methods}

The study design used the sequential explanatory mixed method. The population in this study was students at Universitas Padjadjaran, with a total number of 126 people. This study was conducted in 2014. Inclusion criteria for this study were students at Universitas Padjadjaran and willing to be the respondent, and were from batch of year 2011 to 2013 who were also actively running the program of undergraduate studies at Universitas Padjadjaran, Jatinangor. The exclusion criteria in this study were those who did not fill out the questionnaire data correctly and completely.

This study has received ethical permission from the Health Research Ethics Committee of theFacultyofMedicine,UniversitasPadjadjaran, and got research recommendations from the Faculty of Medicine Universitas Padjadjaran.

This study began with collecting quantitativedata by using a valid and reliable self-administered questionnaire after it was translated to English. Then, the focus group discussions were held along with 2 groups consisting of 6 to 8 people from the same population who discussesed the results of the quantitative data collection. Furthermore, after they were carried out, in depth interviews with mental health experts were held as triangulation to explore why the current perception could be formed. The results of the focused group discussion and in-depth interview were then interpreted qualitatively.

The sampling technique in this study used cluster sampling on faculties at Universitas Padjadjaran, and stratified random sampling on each batch in each faculty. Then, the study data were analyzed using the univariate analysis. This analysis produced a frequency distribution and percentage of existing variables. Formula:

$$
\mathrm{P}=\left(\sum \mathrm{X}\right) / \mathrm{N} \times 100 \%
$$

Specification:

$\mathrm{P}=$ Percentage of respondents rating

$\mathrm{X}=$ total value of respondents

$\mathrm{N}=$ total maximum value of the question

The interpretation of the results were using standard of objective criteria for perception, where the result of "good "was obtained when the $\mathrm{P}$ value was more than $75 \%$, the result of "unfavorable" if they were between $50 \%$ to $75 \%$, as well as the results of " bad " if less than $50 \%$. Then, the collected data was analyzed using a computer software.

\section{Results}

Out of 126 students, about $80.89 \%$ had unfavourable perception towards psychotic disorders, and only a small percentage of students had good perception (Table 1). This study discovered that if the students were divided according to the faculty of origin, the percentage of unfavourable perception was lower compared to the total percentage (Table 2).

Furthermore, knowledge, attitude, and understanding of mental health care were the criteria for forming bad perceptions of Universitas Padjadjaran students towards psychotic disorders. Knowledge became the criterion with the lowest percentage, followed by attitude, then understanding of the health care in sequence (Tables 3,4 , and 5).

In addition, the lack of direct action in the form of campaign by using data and facts of psychotic disorder towards students and the public was the reason that students themselves still lacked insight to psychotic disorders such as diagnosis, treatment, prognosis, and how to overcome the stigma around them.

\section{Discussion}

Moreover, it could be understood that knowledge, attitude, and understanding of mental health care formed criteria of

Table 1 Perception of Universitas Padjadjaran students towards Psychotic Disorders

\begin{tabular}{lcc}
\hline \multicolumn{1}{c}{ Perception Category } & $\begin{array}{c}\text { Frequency } \\
(\mathbf{n = 1 2 6})\end{array}$ & Percentage \\
\hline Good & 24 & 19.05 \\
Unfavorable & 102 & 80.89 \\
Bad & 0 & 0 \\
Total & 126 & 100 \\
\hline
\end{tabular}


Table 2 Perception of Universitas Padjadjaran Students towards Psychotic Disorders per Faculty

\begin{tabular}{lcc}
\hline \multicolumn{1}{c}{ Faculty } & Average (\%) & Perception Category \\
\hline Medicine & 65.93 & Unfavorable \\
Mathematics and Natural Science & 67.22 & Unfavorable \\
Agriculture & 68.80 & Unfavorable \\
Dentistry & 67.87 & Unfavorable \\
Social Science and Polical Science & 69.44 & Unfavorable \\
Cultural Science & 67.41 & Unfavorable \\
Psychology & 62.88 & Unfavorable \\
Animal Husbandry & 64,63 & Unfavorable \\
Communication Science & 68.15 & Unfavorable \\
Nursery & 69.26 & Unfavorable \\
Fisheries and Marine Science & 68.15 & Unfavorable \\
Agriculture Industrial Technology & 68.70 & Unfavorable \\
Pharmacy & 66.67 & Unfavorable \\
Geological Science & 69.26 & Unfavorable \\
Average & 67.45 & Unfavorable \\
\hline
\end{tabular}

perception. ${ }^{4}$ Knowledge became the main determining factor rather than attitude and understanding of mental health care. ${ }^{5}$

Humans formed perceptions through several processes. Initially, when a foreign target was found, we will open ourselves to different information cues and want to learn more about the target. Furthermore, we make efforts to gather more information about the target. We found some familiar properties that help us categorize the target. ${ }^{6}$ We endeavore to look for more cues that confirm categorization

Table 3 Knowledge of Universitas Padjadjaran students towards Psychotic Disorders per Faculty

\begin{tabular}{ccc}
\hline Category & Faculty & Percentage \\
\hline & Medicine & 62.96 \\
Mathematics and Natural Science & 62.96 \\
Agriculture & 62.96 \\
Social Science and Political Science & 66.67 \\
Cultural Science & 64.40 \\
Pnowledge & Psychology & 60.74 \\
& Animal Husbandry & 57.78 \\
Communication Science & 62.22 \\
Fisheries and Marine Science & 61.48 \\
Agriculture Industrial Technology & 66.30 \\
Pharmacy & 59.63 \\
& Geological Science & 67.04 \\
\hline
\end{tabular}


Table 4 Attitude of Universitas Padjadjaran students towards Psychotic Disorders per Faculty

\begin{tabular}{lcc}
\hline Category & Faculty & Percentage \\
\hline & Medicine & 65.18 \\
Mathematic and Natural Science & 67.03 \\
Agriculture & Dentistry & 71.11 \\
Attitude & 66.85 \\
& Cocial Science and Political Science & 69.07 \\
Cultural Science & 68.15 \\
Animal Husbandry & 63.52 \\
Communication Science & 64.07 \\
Nisheries and Marine Science & 71.30 \\
Agriculture Industrial Technology & 68.15 \\
Pharmacy & 69.81 \\
Geological Science & 67.04 \\
\hline
\end{tabular}

of selectively targets. We also actively ignore the nature that violates our initial perception. Our perception become more selective and we finally figure a picture that is consistent with the target. ${ }^{7}$
The shape of perception itself was obtained from a number of factors: the perceiver or people, who are conscious about the suitability to judge, setting or everything which have to do with the environment, the norm around

Table 5 Health Care Understanding of Universitas Padjadjaran students towards Psychotic Disorders per Faculty

\begin{tabular}{ccc}
\hline Category & Faculty & Percentage \\
\hline & Medicine & 70.37 \\
& Mathematic and Natural Science & 71.85 \\
& Agriculture & 70.00 \\
& Dentistry & 71.11 \\
& Social Science and Political Science & 75.18 \\
& Cultural Science & 72.59 \\
Understanding of Health Care & Psychology & 66.67 \\
& Animal Husbandry & 68.15 \\
& Communication Science & 68.52 \\
& Nursery & 71.11 \\
& Fisheries and Marine Science & 73.33 \\
& Agriculture Industrial Technology & 73.70 \\
& Pharmacy & 71.85 \\
& Geological Science & 69.63 \\
\hline
\end{tabular}


them, and idealism as well as the perceiver or the target which is something or someone who assessed. It is closely related to the characteristics of a person's perception, the separation of the individual's background, size, motion, and others. ${ }^{8}$

The theory of planned behavior stated that the attitude toward behavior is a subjective norm (perception) with a foundation of knowledge and perceived behavioral control, together are forming intentions of individual behavior. ${ }^{9}$

As for some of the criteria for the diagnosis of psychotic disorder with signs of delusions, hallucinations, garbled speech, bad behavior, and others could be viewed directly without any treatment or therapy was appropriate and consistent. In prognosis, people who suffer from psychotic disorders could lead a normal life if they get proper treatment and early detection. ${ }^{10}$ Based on a study conducted by Domiguez et al. ${ }^{11}$, it found that the patient's relapse usually occurs if the family is not ready and lacked adequate information to make adjustments to the presence of large family members who experience psychotic disorder.

A study conducted by Emsley et al. ${ }^{12}$ showed that the main cause of relapse in the patient's treatment is ineffective therapeutic regimen which is $60.8 \%$, although knowledge of psychotic disorder is in the high category, bad family attitude towards patients with serious psychotic disorder is $54.9 \%$. Bad behavior towards patients with serious psychotic disorders is $60.8 \%$. At the end, a bad perception of the patient's psychotic disorder leads to relapse as much as $62.7 \%$. Environmental factors are already supporting the patient while in the house supporting the patient is as many as $56.9 \%$, but there are still $43.1 \%$ who state that the environment does not support the patient while at home.

In a study conducted by Corrigan et al. ${ }^{13}$, the public in general assume that people with psychotic disorders are dangerous individuals and are mainly caused by social factors and environment. Subsequently, they are informed about the genetic basis which are also more likely to stigmatize the entire family of the patient. Although certain social categories indicate that the stigma may vary from time to time and place, three basic forms of stigma (physical deformity, bad personal traits, and the status of ethnic outgroups) are found in most cultures and eras, leading some researchers hypothesize that the tendency to stigmatize may have a tendency to form little by little on specific things. ${ }^{14}$
In a similar study conducted in Iraq by Sadik et $a .^{15}$, this bad perception is due to the lack of education about psychotic disorders. It could be enhanced with the access of health services to the community of psychotic disorders, with treatment, and good monitoring to people with a psychotic disorder.

Additionally, perceptions of psychotic disorder may be formed from knowledge, attitude, and understanding of mental health care. The perception of Universitas Padjadjaran students towards psychotic disorders was unfavorable. This perception could form bad behavioral intentions to psychotic disorders. Theseehavioral intentions were not good as they shaped bad behavior to psychotic disorders, such as stigma and discrimination, which will reduce the rate of cure and improve recurrence of the psychotic disorder.

The limitation of this study was some of the students when randomly selected as samples were hard to be found, so the randomization of the sample was repeated in order to fulfill the number of samples.

It can be concluded that the perception of Universitas Padjadjaran students towards psychotic disorders is unfavorable. This perception is formed from a lack of education, campaigns, social media utilization, as well as a bad living experience of people with psychotic disorders. This shows that Universitas Padjadjaran students are illiterate towards psychotic disorders.

\section{References}

1. WHO. Investing in mental health. Geneva: World Health Organization; 2013.

2. Litbangkes RI. Riset Kesehatan Dasar 2013. Jakarta: Kementerian Kesehatan Republik Indonesia; 2013.

3. Dikdik Baehaqi Arif D. Membangun karakter warga negara. Jakarta: Peran (Gerakan) Mahasiswa. 2012.

4. Angermeyer MC, Dietrich S. Public beliefs about and attitudes towards people with mental illness: a review of population studies. Acta Psychiatr Scand. 2006;113(3):163-79.

5. Gureje O, Lasebikan VO, EphraimOluwanuga 0, Olley BO, Kola L. Community study of knowledge of and attitude to mental illness in Nigeria. Br J Psychiatry. 2005;186(5):436-41.

6. Jorm AF, Nakane Y, Christensen H, Yoshioka K, Griffiths KM, Wata Y. Public beliefs about treatment and outcome of mental disorders: a comparison of Australia and 
Japan. BMC Medicine. 2005;3(1):12.

7. Cabeza R, Mazuz YS, Stokes J, Kragel JE, Woldorff MG, Ciaramelli E, et al. Overlapping parietal activity in memory and perception: evidence for the attention to memory model. J Cogn Neuros. 2011;23(11):3209-17.

8. Dufner $M$, Denissen J, Sedikides C, Van Zalk M, Meeus WH, Aken M. Are actual and perceived intellectual selfenhancers evaluated differently by social perceiver. European Jornal of Personality. 2013;27(6):621-33.

9. McEachan RRC, Conner M, Taylor NJ, Lawton RJ. Prospective prediction of health-related behaviours with the theory of planned behaviour: A meta-analysis. Health Psychol. 2011;5(2):97-144.

10. Corcoran CM, First MB, Cornblatt B. The psychotic disorders risk syndrome and its proposed inclusion in the DSM-V: a risk-benefit analysis. Schizophr Res. 2010;120(1):16-22.
11. Dominguez M, Wichers M, Lieb R, Wittchen $\mathrm{H}-\mathrm{U}$, van Os J. Evidence that onset of clinical psychotic disorders is an outcome of progressively more persistent subclinical psychotic experiences: an 8-year cohort study. Schizophr Bull. 2011;37(1):84-93.

12. Emsley R, Chiliza B, Asmal L, Harvey BH. The nature of relapse in schizophrenia. BMC Psychiatry. 2013;13(1):50.

13. Corrigan PW, Morris SB, Michaels PJ, Rafacz JD, Rüsch N. Challenging the public stigma of mental illness: a meta-analysis of outcome studies. Psychiatr Serv. 2012;63(10):963-73.

14. Horsburgh VA, Schermer JA, Veselka L, Vernon PA. A behavioural genetic study of mental toughness and personality. Pers Indiv Differ. 2009;46(2):100-5.

15. Sadik S, Bradley M, Al-Hasoon S, Jenkins R. Public perception of mental health in Iraq. Int J Ment Health Syst. 2010;4:26. 